\title{
Review
}

\section{Palliative Care Among Chumash People}

\author{
James D. Adams $\mathrm{Jr}^{1}$ and Cecilia Garcia ${ }^{2}$ \\ ${ }^{1}$ Department of Molecular Pharmacology and Toxicology, University of Southern California, School of \\ Pharmacy, Los Angeles and ${ }^{2}$ Chumash Healer, Granada Hills, CA, USA
}

\begin{abstract}
Chumash Healers used breathing therapy and counseling to keep patients involved in daily life and to avoid depression. Heat therapy, massage and pain medications were used to help with pain. Another primary function of the Healer was to help the patient sleep as normally as possible, possibly using mugwort or momoy. Nutrition was considered by Healers in treating their patients. The overall concern of the Healer was to help maintain the daily routine of village life during the normal process of the death of a village member.
\end{abstract}

Keywords: breathing - heat - sleep - palliative care

\section{Healing in the Chumash Village}

In the past, everyone in a Chumash village had a purpose, such as canoe maker, acorn gatherer, fisherman and many other jobs. This purpose was crucial to each person. Everyone had earned their place in society and their job for the village. Women earned their place by bearing children. Men earned their place by passing through the momoy ceremony (Datura wrightii) when they were as young as 8 years old (1). Sometimes girls went through the momoy ceremony at puberty (2). This involved drinking a preparation of D.wrightii that is rich in atropine and scopolamine (3). The momoy induced a sacred dream that frequently gave the boys some direction about their future lives. The boys carved a soapstone dream guide ('atishwun pronounced gatteeshwun) after their dream. The dream guide was used as a spiritual talisman for the rest of their lives. Each person was either assigned a job, or found a job as the result of dreams of the future, perhaps induced during the momoy ceremony. The Healer was one of the people who reminded people about their value to the village and kept the people working. It was the Healer's job to keep everyone well and keep them working. The Healer recognized that hard work keeps people physically and spiritually healthy and happy.

For reprints and all correspondence: James D. Adams Jr, Associate Professor of Molecular Pharmacology and Toxicology, University of Southern

California, School of Pharmacy, 1985 Zonal Avenue, PSC 508, Los Angeles,

CA 90089-9121, USA. Tel: +1-323-442-1362; E-mail: jadams@usc.edu
However, when a person became very old or was seriously ill or injured, the Healer's job became keeping the person alive. Each person was vital to the survival of the village. So it was critical to keep people going. The Healer had many skills in this regard.

It is not uncommon for old people to become depressed, perhaps due to changes associated with aging or the loss of loved ones. The Healer treated depression by keeping each person involved in their normal daily tasks. Even simple tasks such as pounding acorns to make acorn meal can help with depression. This may be due to mental relaxation associated with simple, repetitive tasks. It may also be that continuing to perform normal tasks to keep the village functioning helps people feel better about themselves.

\section{Restoring Breathing}

Chumash Healers may work with dying patients to encourage breathing. Breathing may become a primary concern in patients approaching the end of their lives. Proper breathing may help keep them alert, which in turn may help keep them focused on normal daily activities such as bathing and grooming. In the old days, Chumash people bathed every day before the sun rose (1). One very effective way to encourage people to breathe is to sing with them. Singing requires proper breathing. The rhythm of the song may also encourage their breathing. Chumash did not use drums. Instead they had clapper sticks, made by splitting $1 \mathrm{~m}$ long limbs of Sambucus mexicana

(C) The Author (2005). Published by Oxford University Press. All rights reserved.

The online version of this article has been published under an open access model. Users are entitled to use, reproduce, disseminate, or display the open access version of this article for non-commercial purposes provided that: the original authorship is properly and fully attributed; the Journal and Oxford University Press are attributed as the original place of publication with the correct citation details given; if an article is subsequently reproduced or disseminated not in its entirety but only in part or as a derivative work this must be clearly indicated. For commercial re-use, please contact journals.permissions@oupjournals.org 
(elderberry, Fig. 1a) for most of the length of the limb. The limbs were typically $3 \mathrm{~cm}$ or so in diameter. When struck against the palm, the sticks make a loud, percussive sound. Clapper sticks were used to accompany singing and may have been given to people who needed to be encouraged to breathe properly. The elderberry plant is also called the tree of music. It represents the heart beat of the Chumash people and their music.

'It is important to help people remember to breathe. Sometimes, just getting them to sing can help them breathe better. It is almost like they are waking up as they begin to sing and breathe'. (Cecilia Garcia)

Yerba santa (Eriodictyon crassifolium or E. trichocalyx) was used to help keep airways open for proper breathing $(1,3)$. Yerba santa was used for any breathing problem, including tuberculosis. This condition may have occurred in California before the Spanish arrived, but became much more prominent afterwards. Yerba santa contains several active flavonoids including eriodictyol, which has antibiotic, anti-inflammatory and expectorant activities (3). Other flavonoids include homoeriodictyol, pinocembrin, sakuranetin, cirsimaritin and others. Yerba santa (E. californica) was an approved medicine in the USA for use in the management of airway infections until 1960 when it was removed from the market. At that time, a law was passed requiring that all medicines must have proven efficacy. No one was willing to pay to conduct clinical trials of yerba santa.

Yerba santa was also used as a poultice on the chest to help with breathing and relaxation. Yerba santa leaves were heated in warm water with California bay leaves (Umbellularia californica) and the crushed bulbs of red skinned onion (Allium haematochiton) or any similar onion. The yerba santa helped open the breathing passages. The California bay leaves helped provide a warm, soothing sensation to the chest and a pleasant smell due to the presence of monoterpenes such as cineole, umbellulone and sabinene (3). The onion helped stimulate the sense of smell, which in turn helped stimulate breathing. Onions contain alliin, ajoene and other pungent-smelling compounds (3). (a)

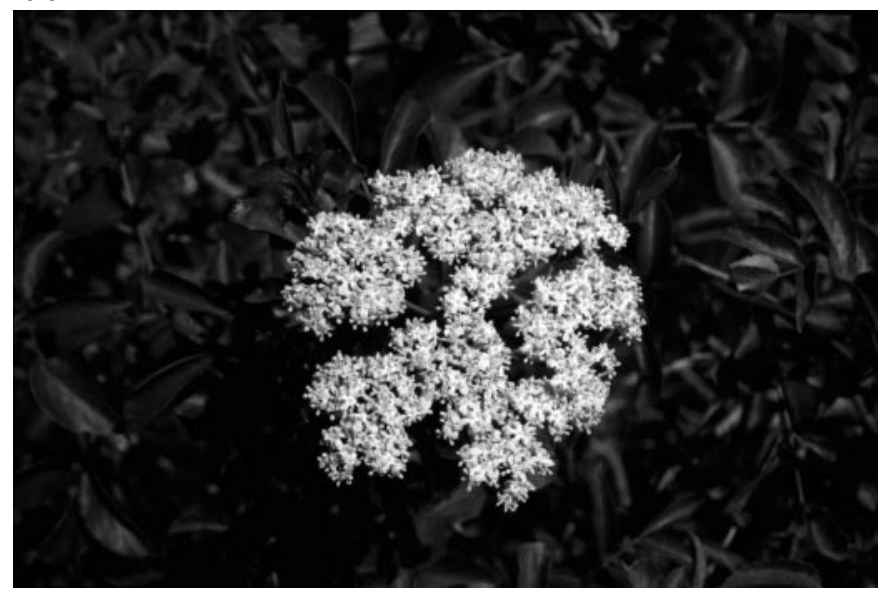

(c)

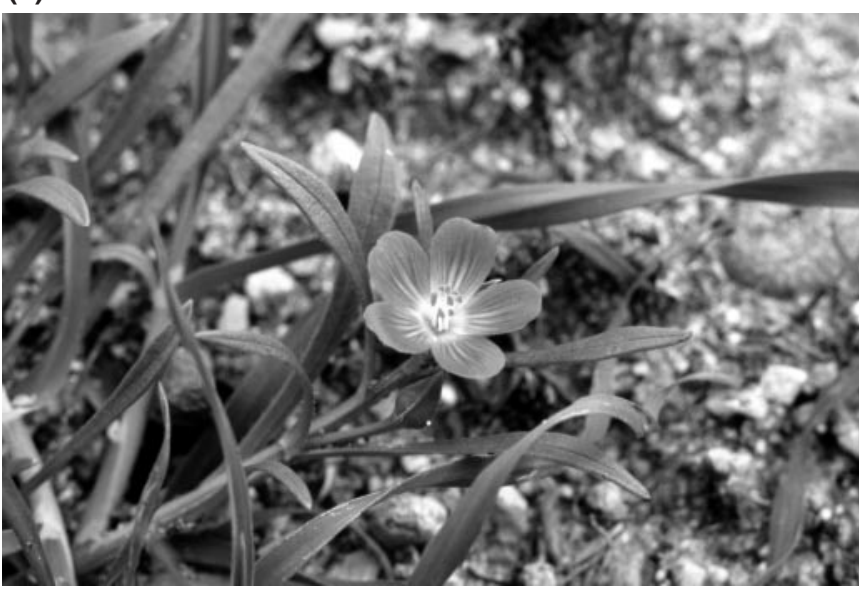

(b)

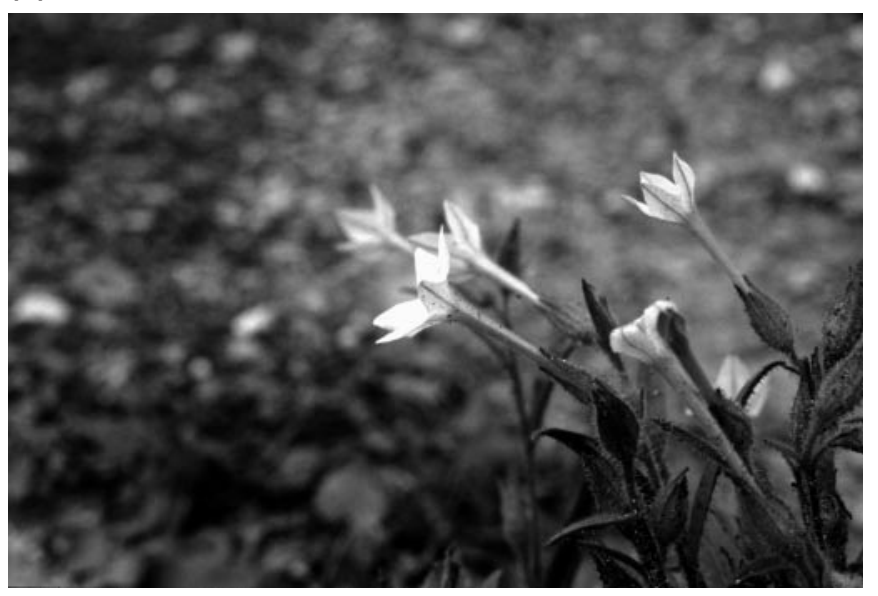

(d)

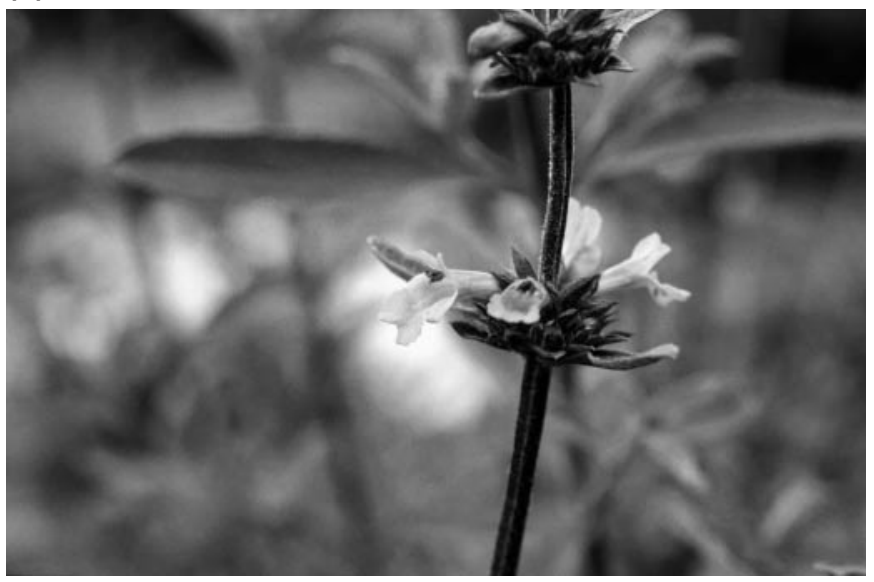

Figure 1. Plants used in palliative care. (a) Sambucus mexicana, elderberry: uses include making clapper sticks from the wood, treating colds and flu with a tea made from the blossoms and other uses. (b) Nicotiana quadrivalvis, California tobacco: uses include chewing the leaves to decrease hunger and maintain alertness, burning the leaves as an offering to God and other uses. (c) Calandrinia ciliata, red maids, khutash: uses include eating the toasted seeds and using the flowers as offerings in sacred hot springs. (d) Salvia mellifera, black sage: uses include relief of pain by external application of a decoction of the leaves and other uses. 
'I like to use a poultice of yerba santa, bay and onion to help people breathe. I put the wet leaves on the chest and ask them to breathe. The onion gives them something pungent to stimulate their breathing'. (Cecilia Garcia)

A tea of tobacco (Nicotiana quadrivalvis, Fig. 1b, or $N$. attenuata) and elderberry blossoms was made to help with pain and to keep the airways open to promote breathing. Tobacco contains nicotine, a stimulant that can stimulate breathing (3). Nicotine can also help alleviate pain by interaction with brain nicotinic acetylcholine receptors that moderate pain (4). Elderberry blossoms, such as from Sambucus nigra, provide effective therapy against flu and colds (3). The blossoms contain cyanins and other compounds such as flavonoids, lectins, triterpenoids, sterols, tannins and aromas that may have activity against viruses or may promote clearing of the airways (3). Chumash and other California Indians used elderberry blossoms routinely against colds and flu (3).

\section{Heat Therapy for Pain}

Heat is commonly used for the treatment of pain associated with arthritis and other chronic conditions. Heat therapy was very important for dying patients. It helped revitalize them and helped alleviate pain. Among Chumash, sweat lodges, natural hot springs and warm rocks were used for heat therapy. Sweat lodges were typically dug into the ground about $1.5 \mathrm{~m}$ deep and covered with a dome of woven willow branches (Salix lasiolepis). Willow branches were $\sim 3 \mathrm{~cm}$ or more in diameter. The dome was plastered with clay from a nearby creek to a thickness of $5 \mathrm{~cm}$ or more. After allowing the clay to dry for several weeks, a fire was built inside, and perhaps outside, to bake the clay. The sweat lodge was typically $10 \mathrm{~m}$ or more in diameter, nearly $2 \mathrm{~m}$ high on the inside and had a single opening at the top. The opening served as a smoke hole and an access door. A ladder inside the sweat lodge allowed people to enter or leave through the hole. The lodge was heated by building a fire in the center. This provided temperatures of $40^{\circ} \mathrm{C}$ or more near the center and cooler temperatures farther from the fire. Men used the sweat lodge almost daily for heat therapy and purification. White sage (Salvia apiana) leaves were chewed or rubbed on the body as part of this purification. White sage contains cineole and other monoterpenoids that are soothing, and diterpenoids and miltirone that relieve pain and anxiety (3). Women also used sweat lodges for heat therapy. Old people used the sweat lodges for heat therapy regularly. Sweat lodge therapy involved the use of special tools to scrape sweat from the body. These sweat scrapers (stirgil in Chumash, pronounced steerjeel) were sometimes made from deer ribs or other long, thin bones (5). Typical heat therapy sessions should last $\sim 15 \mathrm{~min}$ and should be followed by $1 \mathrm{~h}$ of recuperation and rehydration before another heat therapy session.

There are many hot springs in Chumash territory. These springs are naturally heated and provide hot water all year round. These springs were regularly used for heat therapy, especially by people with arthritis pain. Sometimes dying people were carried to the springs for heat therapy. Aromatherapy was also used in these hot springs by putting several handfuls of California bay leaves (U.californica) in the spring. This fills the water and the air with the smell of bay. Bay contains monoterpenes such as cineole, sabinene, umbellulone and thujene that may act as pain relievers (3). In the spring, the hot springs were used for a sacred ceremony honoring Khutash, the Spring Goddess. The hot springs were blessed and scented with California bay and decorated with red maids (Calandrinia ciliata, Fig. 1c) which are called khutash in Chumash. Following this sanctification of the spring, people bathed (1). As with the sweat lodge, heat therapy should last $\sim 15$ min followed by $1 \mathrm{~h}$ of recuperation and rehydration.

Rocks were heated in hot springs or sweat lodges and used for heat therapy, especially for aching feet. However, heated rocks could be used for heat therapy on other parts of the body as well, especially for dying people. Rocks should not be heated in a fire, which makes the rocks too hot. When heating a rock in the sweat lodge, it is important to choose a rock that is dry and has not been in a stream. Stream rocks can explode when heated due to water inside the rock that forms steam and expands explosively.

'Many older people like to put their feet on warm rocks. I like to have warm rocks for them when we sit around the fire at night and sing'. (Cecilia Garcia)

Heat therapy was also supplied by breathing steam from hot water. Water was heated in water-tight baskets by putting a hot rock into the basket and stirring with a stick to keep the basket from burning. The patient, perhaps suffering from a respiratory ailment, then breathed the steam to keep the airways open and clear of mucus.

Heat therapy sometimes involved building a fire in a small cave. When the fire was hot enough, the dying, injured or very sick patient was partially buried in warm sand and kept in the cave. The warm sand helps heat the patient quickly and provides some insulation against possibly excessive heat from the fire. Of course, it was important to keep the patient's head near the opening of the cave to avoid carbon monoxide poisoning. As with sweat lodge therapy, this therapy should last $\sim 15 \mathrm{~min}$ with a $1 \mathrm{~h}$ break between sessions.

\section{Healing Touch}

Massage is an important tool used by Chumash Healers to treat both acute and chronic pain, especially in palliative care. Massage is a gentle reminder to patients in pain that someone cares about them. This is especially important in what is called Alzheimer's disease today and in other patients who may not be very aware of other people around them and may feel isolated. Touch is comforting and relaxing. This relaxation helps patients adjust to pain and helps them control their pain (6). Massage typically involves careful manipulation of painful areas. Massage promotes blood flow that can help clear lactic acid and other metabolic products that may have acccumulated in an area. Of course, lactic acid promotes cramp, which is very painful. In addition, adjusting may be performed by manipulating areas that are not painful, in order to help relieve 
pain in remote, painful areas. For instance, lower back pain may be treated by adjusting the area between the thumb and forefinger. The art of adjusting requires at least 7 years of training for the Healer to be able to perform the techniques. Some Healers are known to have the gift of touch. Their touch is medicine that cures. This gift of touch is a gift from God that not every Healer is given.

\section{Pain Medications}

Chumash people had several medicines used against pain such as willow (S.lasiolepis), momoy (D.wrightii) and black sage (Salvia mellifera, Fig 1d). These medicines were routinely used in the treatment of pain in dying patients. Pain and fever relief occurs after chewing one or two willow leaves. Willow contains salicylates such as salicin, salicortin, tremulacin and others (3). These salicylates are oxidized in the liver to produce salicylic acid which is an anti-inflammatory agent. As with all salicylates, gastrointestinal and other toxicity is possible from overuse of willow.

Momoy is also called California jimson weed. Momoy is the Chumash word for the plant (3). Of course, jimson weed refers to Jamestown, Virginia. The plant that grows in Virginia is Datura stramonium, which has most of the same activities as momoy. The use of momoy in pain treatment involves making an extract for external use. The extract is made by allowing $\sim 0.25 \mathrm{~kg}$ of the stems and roots of the plant to brew in $\sim 11$ of water in the sun for several days. The extract is a brown color. One or two white sage (S.apiana) leaves are added in the final hour of brewing. White sage gives the brew a pleasant sage smell. This extract is rubbed onto painful areas of the legs and arms. Momoy contains atropine, scopolamine and other compounds that may relieve pain (3). White sage contains a number of monoterpenes and other compounds that may facilitate pain relief. It is important to point out that both momoy and white sage are considered spirit plants by Chumash Healers. These plants treat the spirit and adjust the spirit. This helps make the body well.

Black sage is a plant used to treat the body and pain in the body. A handful or more of crushed black sage leaves and stems is placed into a bath of $\sim 4$ of warm water. After several minutes of brewing, the feet are placed into the bath. Soaking in the bath helps relieve pain in the feet and lower legs. White sage leaves can also be added to the bath. The patient may be instructed to massage the bottoms of the feet in the bath. This is done by placing portions of deer antlers in the bath. The patient places their feet on top of the antlers and rocks the feet back and forth. This is a very comforting, nice smelling procedure that everyone enjoys. Black sage contains anti-inflammatory compounds such as diterpenoids, aethiopinone and ursolic acid (3).

Swelling of the feet and legs is a common and painful condition that occurs in patients suffering from congestive heart failure, kidney disease and other conditions. Chumash Healers treated lower leg edema with kelp wraps. Kelp is Fucus vesiculosus and is a common seaweed along the Californian sea coast. The plant has leaves up to several meters long and $\sim 6 \mathrm{~cm}$ wide. The leaves can be wrapped around the leg, but not too tightly, in order to help with edema. Kelp contains phytosterols (7) that may help with water resorption in the kidney and decrease edema.

\section{Sleep Disturbances}

Sleep disturbances are common in elderly and dying patients. Sleep and dreaming were typically induced with mugwort (Artemisia douglasiana) as discussed previously (8). However, in dying patients, sleeping is more difficult. Sometimes momoy was used to induce sleep. The preparation discussed above or similar preparations of other parts of the plant, such as the flowers, were used internally. Momoy preparations had to be used carefully due to the potential toxicity of atropine and scopolamine in the plant. These preparations were not used to take the life of a dying person. These people had already earned their place in society and were valuable members of the village. However, momoy is the plant that prepares us for changing from one stage of life to another. It was used in coming of age ceremonies as discussed above, when boys were prepared to become men. Momoy may help dying people, spiritually, to prepare for the next stage of existence.

\section{Diet and Maintaining Weight}

The elderly and the dying tend to lose weight. This may involve general wasting, as in cancer, or changes in appetite, especially in Alzheimer's disease patients. These patients tend to prefer sweet foods. In the old days, elderberries and toyon berries (Heteromeles arbutifolia) were fed to Alzheimer's disease patients. It was believed these sweets helped them with the disease process. The berries certainly could have helped them to maintain their weight. There have been no investigations into the compounds found in toyon berries. Elderberries are discussed above.

Traditional practices dictated many dietary restrictions, called saxtin (pronounced sahteen) in Chumash. For instance, when using momoy, it was forbidden to eat meat or animal fat (1). Momoy was a woman who, as directed by God, originally created the plant that bears her name. There are several legends about Mother Momoy (9), who could be thought of as a Chumash saint. Disrespecting the spirit of Momoy by eating meat or fat could have detrimental effects on the patient. Saxtin also involved abstinence from sex. Saxtin was invoked for many cures, as a type of fasting, and was considered to make the patient more spiritually fit for a cure.

\section{The Family of a Dying Person}

The family of a dying patient was prepared for the inevitable by the Healer and other members of the community. This involved prayer, counseling and advice. The family was also encouraged to participate in the healing process by praying, undergoing saxtin and perhaps other symbolic or spiritual acts for the patient. The goal was to avoid depression among family 
members and keep them active and contributing to the welfare of the village.

\section{Conclusions}

The Healer prayed with dying patients and counseled them to help with distress and fear of the unknown. The Healer reminded the patient about what was known about the afterlife. The soul would depart from the body, but stay in the area for up to 3 days. It was then the duty of the soul to leave the village area and fly to Point Conception, north of Santa Barbara. From there, the soul would fly west across the sea to Similaqsa, the Chumash Heaven. The Healer would advise the patient about potential dangers that could prevent the soul from entering Similaqsa. These are described in Chumash legends (9).

Eventually the patient and the Healer agreed that it was time to prepare for death. The Healer respected this process and did not seek to prolong life after this. As the patient became unable to perform normal sanitary tasks, a homosexual person was assigned to care for the patient during the final days. A homosexual woman would be assigned to care for a dying man. A homosexual man would be assigned to care for a dying woman. These respected care givers had the tasks of feeding, cleaning and sleeping beside the dying. The purpose of this was to eliminate sexuality from the process and provide the dying patient with a caring person who could stay with them and comfort them in their last days. When the patient died, the homosexuals of the village or nearby villages prepared the body for burial.

\section{Supplementary Data}

Supplementary data are available at $e C A M$ online.

\section{References}

1. Walker PL, Hudson T. Chumash Healing: Changing Health and Medical Practices in an American Indian Society. Banning: Malki Museum Press, 1993.

2. Gibson RO. The Chumash. New York: Chelsea House Publishers, 1991.

3. Garcia C, Adams JD. Healing with Medicinal Plants of the WestCultural and Scientific Basis for Their Use. La Crescenta: Abedus Press, 2005.

4. Jain KK. Modulators of nicotinic acetylcholine receptors as analgesics. Curr Opin Invest Drugs 2004;5:76-81.

5. Miller, BW. Chumash: A Picture of Their World. Los Osos: Sand River Press, 1988.

6. Astin JA. Mind body therapies for the management of pain. Clin J Pain 2004;20:27-32.

7. Skibola CF. The effect of Fucus vesiculosus, an edible brown seaweed, upon menstrual cycle length and hormonal status in three pre-menopausal women: a case report. BMC Comp Altern Med 2004;4:10.

8. Adams JD, Garcia C. The advantages of traditional Chumash healing. eCAM 2005;2:19-23.

9. Blackburn TC. December's Child: A Book of Chumash Oral Narratives. Berkeley: University of California Press, 1975.

Received January 28, 2005; revised March 17, 2005; accepted April 4, 2005 


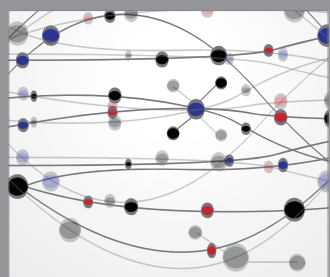

The Scientific World Journal
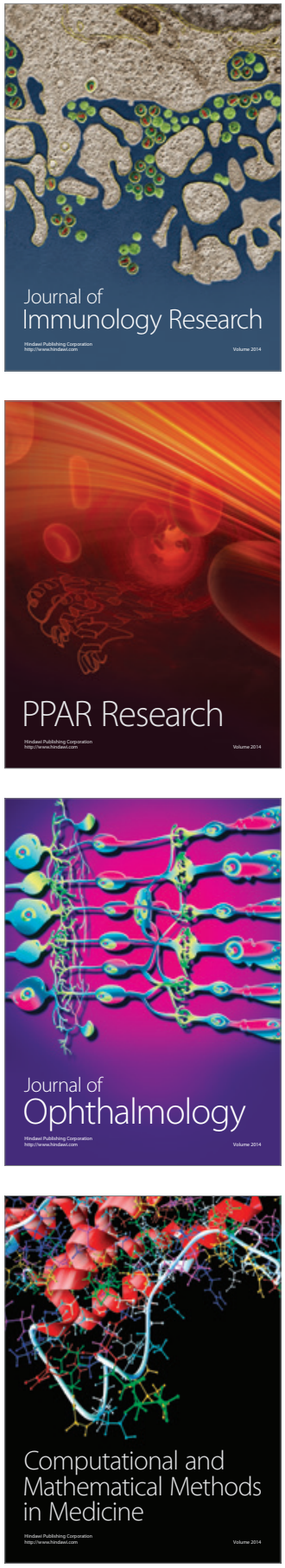

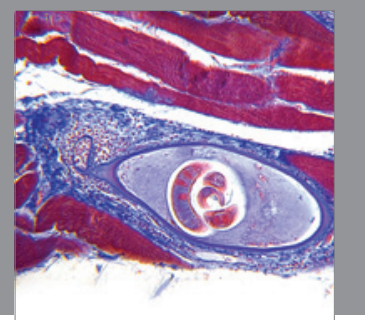

Gastroenterology

Research and Practice
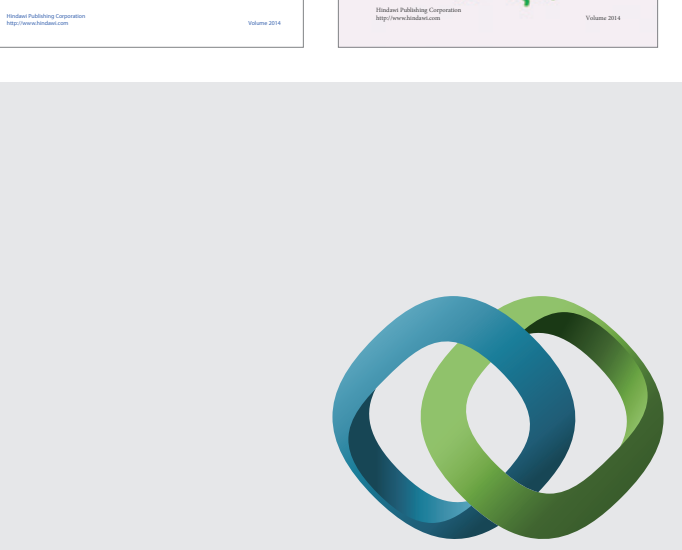

\section{Hindawi}

Submit your manuscripts at

http://www.hindawi.com
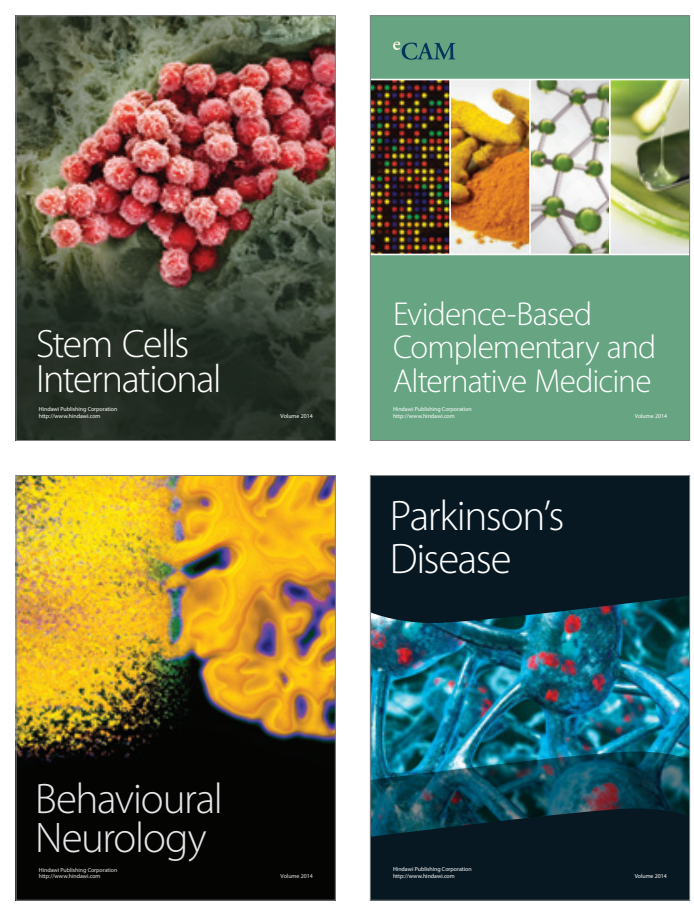

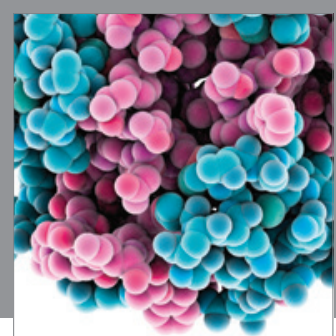

Journal of
Diabetes Research

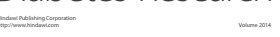

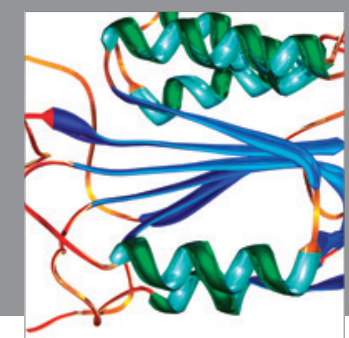

Disease Markers
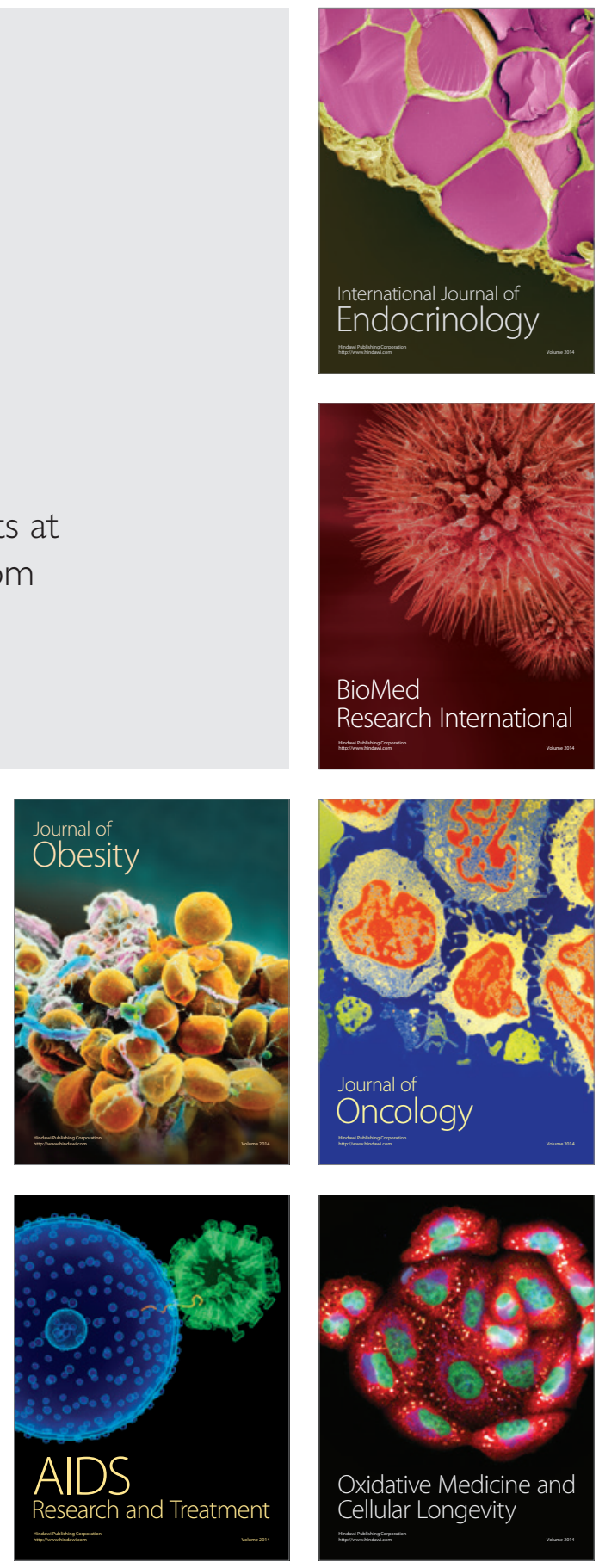